\title{
Porous Silica for Removing Organic Impurities from Wastewater
}

\author{
By Hussien Motaweh* \& Marwa Nabil
}

\begin{abstract}
In this study, the production of different architectures of two type's porous silica (amorphous and crystalline) is shown, using simple and inexpensive dual technique (alkali chemical etching process and ultra-sonication). The chemical, physical and morphological properties are the master factors, which produce a variety of application fields. It has been decided the importance degree of the porous spherical shape; as one of the most important architectures, that assist the dyes adsorption process in various industrial fields as (foods, pharmaceutics industries, and the textile industry). As it increases the breadth of the surface area of the material and it can also be used as thermal insulation due to increased electrical resistance and thermal material as well as chemical stability. Thus, we demonstrated the importance of devising different properties of the material for reuse in different applications in many applied fields. This study discusses how to remove many organic pollutants (dyes and oils) from wastewater. Therefore, the study reviewed many sizes and shapes of porous silica in different buildings, which opens the way for us to use in new applications. The both promise percentages of oil and Congo red removal are 100\% and 99.8\%, respectively. The amounts of used synthesized powder are very fine in each; $(0.7 \mathrm{gm} / \mathrm{L})$ of amorphous porous $\mathrm{SiO}_{2}$ for oil removing and $33.3 \mathrm{gm}$ of crystalline porous $\mathrm{SiO}_{2} / \mathrm{l}$ (at congo red concentration $50 \mathrm{ppm}$ ).
\end{abstract}

Keywords: Electrical Resistance, Morphology, Porous Silica, Thermal Resistance.

\section{Introduction}

Silica particles have been widely used due to their chemical stability, biocompatibility, non-toxicity and relatively easy synthesis, enabling adjustable size, morphology and porosity (Nikolić et al. 2016). In recent years, the studies of nanoparticles and nanostructures have attracted increasing interests worldwide. Porous nanospheres can potentially provide the advantages of both nanoparticles and high surface areas from micro-and mesopores in the nanoparticles (Ahmad et al. 2010).

Porous materials are solids that contain empty pores dispersed within their framework (Xiong et al. 2016). The pores may be open pores connecting to the outside of the material or closed pores isolated from the outside. Porous materials have lower density and higher surface area compared with dense materials (Morsi and Mohamed 2018). Porous Silica (Porous $\mathrm{SiO}_{2}$ ) from renewable sources can be used in very different materials, such as paints (Castillo et al. 2014), membranes for fuel cells (Zakarya et al. 2009), Li-ion batteries (Lisowska-Oleksiak et al. 2014), adsorbents (Lee et al. 2016), catalysts (Bernardos and Kouřimská 2013), and so on. The synthesis of (Porous $\mathrm{SiO}_{2}$ ) has greatly expanded the possibilities

\footnotetext{
"Professor and Vice Rector, Damanhour University, Egypt.

*Researcher, Advanced Technology and New Materials Research Institute, City for Scientific Research and Technology Applications, Egypt.
} 
for the design of open pore structures. Porous $\mathrm{SiO}_{2}$ has great potential in environmental and industrial processes, because of its large surface area, pore size and pore shape (Feng et al. 1997).

Nowadays the most promising technique for treating wastewater is adsorption process (i.e adsorbents agro-industrial) (Rovani et al. 2018). Porous $\mathrm{SiO}_{2}$ produced from commercial silicon has also been applied as green adsorbents (Nabil and Motaweh 2019). The main factors, which effect on the adsorption success in wastewater are the values of the porosity degree, the internal surface area, and the favorable chemical surface of the adsorbents. Several studies have already used porous $\mathrm{SiO}_{2}$ for the adsorption of organic contaminants with success (Mahmoodi et al. 2014).

Functional groups were introduced to the porous surface of porous $\mathrm{SiO}_{2}$ as the terminal groups of organic monolayers. So, the siloxane groups undergo hydrolysis, become covalently attached to the substrate and cross-linked to one another (Feng et al. 1997).

In this paper, two types of porous $\mathrm{SiO}_{2}$ particles (amorphous and crystalline), with different structures, functionalities and sizes are synthesized using the dual technique (i.e. alkali chemical etching and ultra-sonication) for available commercially silicon, porous $\mathrm{SiO}_{2}$ can be synthesized in bulk form, which can be produced in large quantities. The effect of porous $\mathrm{SiO}_{2}$ particle type on adsorption efficiency of organic impurities is also investigated. It is showing the dependence of adsorbent material on the variety of porous $\mathrm{SiO}_{2}$ morphological shapes. In addition, it shows the removal percentage of organic impurities (dye, and oil) that present in wastewater.

\section{Methodology}

\section{Porous $\mathrm{SiO}_{2}-$ Powder Preparation}

The dual technique (Ultra-sonication technique and the alkali chemical etching process) is used in porous $\mathrm{SiO}_{2}$ preparation (Nabil et al. 2018). The suitable amount of silicon powder (silicuim, Pulver-99\%), was scattered in a solution that contains different concentrations of $\mathrm{KOH}$, 1-propanol (30 vol \%), and water for different sonication times. The product powder is dried after filtration process.

The structure of the porous $\mathrm{SiO}_{2}$ powder were characterized by X-ray diffraction (XRD; using $\mathrm{Cu} \mathrm{K \alpha}$ radiation of $1.5405^{\circ} \mathrm{A}$ at a scanning rate of $4^{\circ}$ $\min ^{-1}$, Shimadzu 7000 diffractometer). The formation of chemical bonds for the formation of $\mathrm{P}-\mathrm{SiO}_{2}$ powder was determined by Fourier Transform Infrared (FTIR) spectroscopy FTIR-8400 S spectrophotometer, Shimadzu, Japan from the various vibrational modes (each infrared spectrum was collected from 400 to 4000 $\mathrm{cm}^{-1}$ ). Porous $\mathrm{SiO}_{2}$ powder morphology is investigated using SEM (Scanning electron microscopy, JEOL (JSM 5300), magnification from 500 to 27000, at an accelerating voltage of $10 \mathrm{kV}$.

Porous $\mathrm{SiO}_{2}$ Applications 
Batch Equilibrium Method (Sharma et al. 2009); it was selected because of its simplicity and reliability. All experiments were executed at room temperature (27 ${ }^{\circ} \mathrm{C}$ ) in batch mode. They were done by taking $40 \mathrm{ml}$ metal ion sample (AR grade) in a $100 \mathrm{ml}$ Erlenmeyer flask and after $\mathrm{pH}$ adjustments; a known quantity of solution dried adsorbent (Porous $\mathrm{SiO}_{2}$ ) was added.

The flasks were shaken at $200 \mathrm{rpm}$ for time rounds till equilibrium conditions. After the shaking process, it became suspension. The residual biomass adsorbed with soya beam oil molecules and Congo red dye molecules, the filtrate was collected and subjected for guest molecules. The filtrated solution is estimated using (FTIR) spectroscopy. The values of percent oil and dye uptake by the sorbent (Sorption efficiency (Aminu et al. 2010) and the amount of it, has been calculated using the mathematical relations in our previous research (Nabil and Motaweh 2018).

\section{Results}

Figure 1 presents SEM-micrographs of synthesis porous $\mathrm{SiO}_{2}$ powder morphology. The pores interconnection is the most important structure characteristics of porous $\mathrm{SiO}_{2}$ prepared in this work, as shown in Figure 1a, b, c, and d, by which the type of application is determined. The spongy shape (Yan et al. 2009), appears in Figure 1, a, b, which is formed at preparation conditions $(6 \mathrm{wt} \% \mathrm{KOH}$ and 30 vol \% n-propanol). Its pore size is in range $(0.06-0.35 \mu \mathrm{m})$. So, it's ready to adsorb the oil molecules, due to the large size of the oil molecule (Jokić et al. 2013), as shown in the following. Oils are nonpolar (Nwabueze and Okocha 2008), and as a result they're not attracted to the polarity of water molecules. In fact, oils are hydrophobic, or "water fearing". Instead of being attracted to water molecules, oil molecules are repelled by them. Because oil is less dense and has higher viscosity than water (Vuong et al. 2009), it will always float on top of water, creating a surface layer of oil. So, the synthesis porous $\mathrm{SiO}_{2}$ powder is suitable to remove the oil from waste water as presented in the following (Santos et al. 2014).

Either in case of the $\mathrm{KOH}$ concentration ( $3 \mathrm{wt} \%)$, Figure 1c and d show the formation of micro-wires $\mathrm{SiO}_{2}$ (wire length in the range 380-2297 $\mu \mathrm{m}$ and the wire width in the range $0.8-6.5 \mu \mathrm{m}$ ). Then, the outer surface of the micro-wires $\mathrm{SiO}_{2}$ is the active area of adsorption process. It permits the adsorption process in a wider manner, whatever the size of the particles of the adsorbed substance (small or large).

Also, XRD is very useful technique for studying the crystal structure changes, which are produced by etching processes as a result of using the dual technique, as shown in Figure 1e (Russo et al. 2011). It displays the diffraction features of the $\mathrm{SiO}_{2}$ NPs broadened peak of powders that appears at around $2 \theta=20^{\circ}$ with high intensity (Nabil and Motaweh 2015) and (Abou- Rida and Harb 2014). That is produced by consecutive chemical erosion processes with different $\mathrm{KOH}$ concentrations ( 3 and $6 \mathrm{wt} \% \mathrm{KOH})$. Noticeable, the powder product wasn't separated from the etchant solution. It corresponds to amorphous $\mathrm{SiO}_{2}$. 
Figure 1. Scanning Electron Micrographs of Porous $\mathrm{SiO}_{2}$ obtained with $(a, b) 6$ wt \% $\mathrm{KOH}(c, d) 3$ wt \% KOH (c) Without Separation Process, and (e) X-ray Diffraction Patterns of Amorphous Porous $\mathrm{SiO}_{2}$ Obtained at (6, and 3 wt \% KOH)
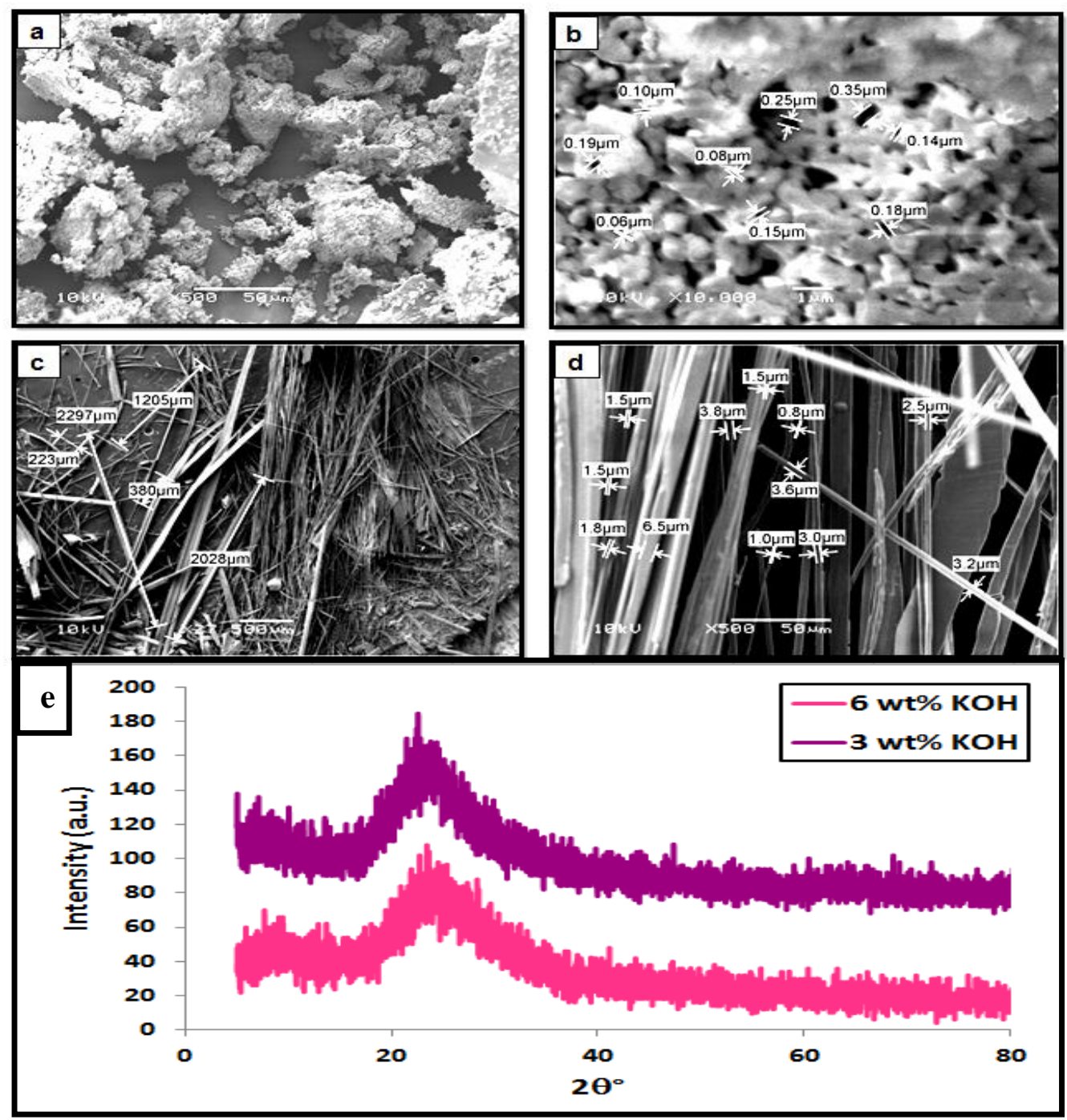

Figure 2 shows $\mathrm{SEM}$ images of porous $\mathrm{SiO}_{2}$ powder product. It clearly shows three different porous architectures (sheets, rod array, and clusters) (Singh et al. 2011), which is as a result of using $\mathrm{KOH}$ concentration $=6 \mathrm{wt} \%$ at several sonication times, after separation process of the product powder and drying it at $40^{\circ} \mathrm{C}$. Figure $2 \mathrm{a}$, and $\mathrm{b}$ show the porous $\mathrm{SiO}_{2}$ sheets, at the sonication time (t) $2 \mathrm{hr}$, its lengths are in the range 3.3-9.9 $\mu \mathrm{m}$. The diameter of the porous $\mathrm{SiO}_{2}$ rods array is in the range $(0.634-0.894 \mu \mathrm{m})$ and its length is $\approx 3.12 \mu \mathrm{m}$ with a smooth porous surface, which is formed at $\mathrm{t}=3 \mathrm{hr}$, as shown in Figure 2c, and $\mathrm{d}$. In addition, its pore size is $(28-140 \mathrm{~nm})$. The third architecture is porous $\mathrm{SiO}_{2}$ clusters that are formed at $\mathrm{t}=4 \mathrm{hr}$, as shown in Figure 2e and $\mathrm{f}$. The powder product porous $\mathrm{SiO}_{2}$, with different architectures, is most suitable for using in water treatment process (for settling heavy metals, dyes and other mineral) (Chaemiso and Nefo 2019), as 
shown in our previous study (Nabil and Motaweh 2018). So, the porous $\mathrm{SiO}_{2}$ surface area is more useful than the commercial silicon powder for many environmental applications (Juárez et al. 2016); as a removing of different dye types and heavy metals in wastewater for recycling use (Kaykhaii et al. 2018).

Figure 2. Scanning Electron Micrographs of Porous $\mathrm{SiO}_{2}$ obtained with 6 wt \% $\mathrm{KOH}(a, b)$ Micro-Sheets at $t=2 \mathrm{hr}(c, d)$ Rod-Clusters at $t=3 \mathrm{hr}(e, f)$ Clusters at $t=4 \mathrm{hr}$, and $(\mathrm{g}) \mathrm{X}$-ray Diffraction Patterns of Crystalline Porous $\mathrm{SiO}_{2}$ Obtained

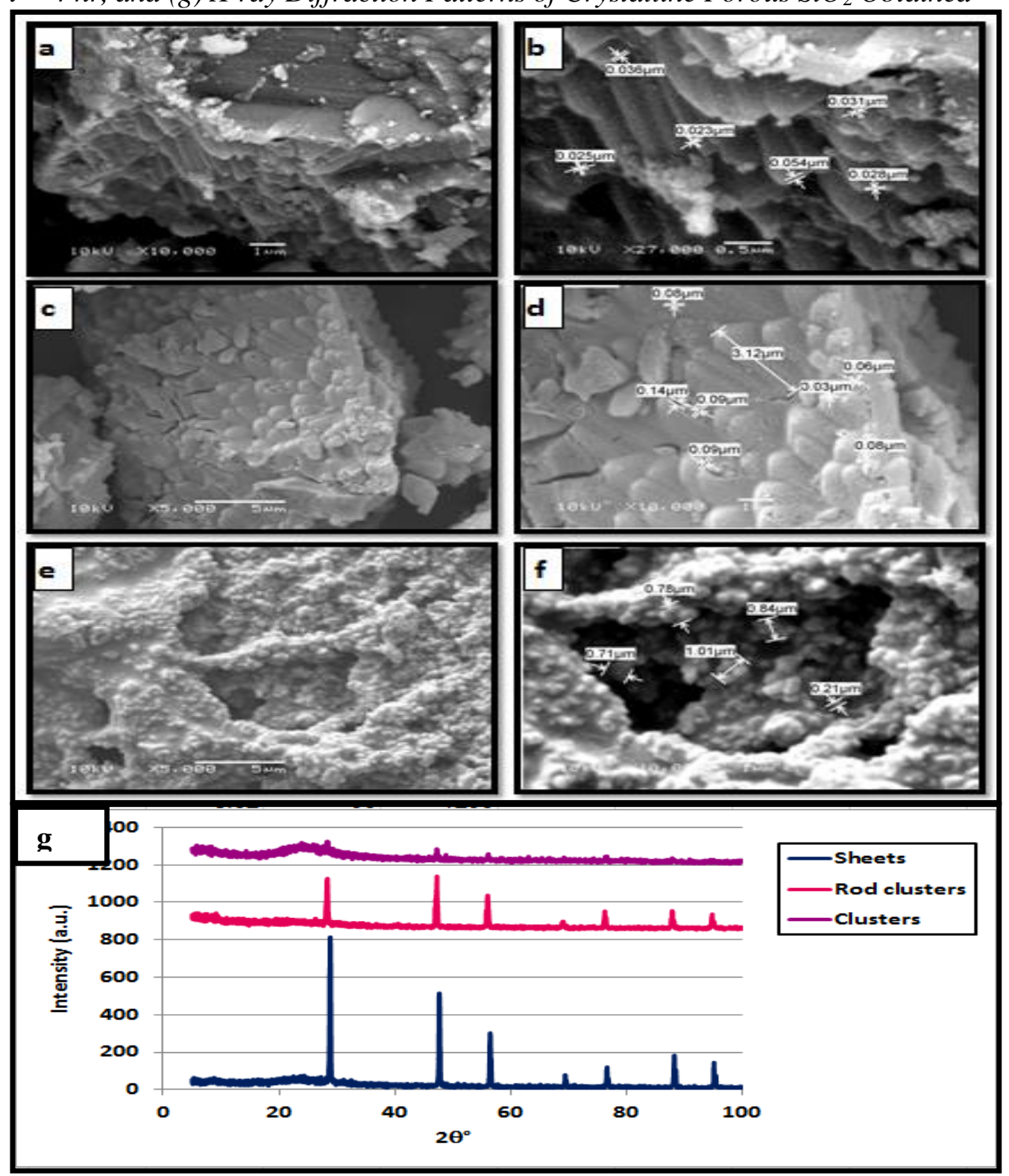

And for studying the plane form of the last architecture, XRD shows the crystalline porous $\mathrm{SiO}_{2}$ formation (Narayan et al. 2018), as shown in Figure 2g. It shows the position in the diffraction pattern at around $28.22^{\circ}, 47.21^{\circ}, 56.02^{\circ}$, $68.88^{\circ}, 76.27^{\circ}, 87.91^{\circ}$, and $94.78^{\circ}$ (JCPDS card nos. 01-079-0613 and 00-0271402) (Kashyout and Nabil 2018). They correspond to crystalline planes (111), 
(220), (211), (400), (331), (422), and (511), respectively (Joni et al. 2018). In addition, each plane of the crystalline porous $\mathrm{SiO}_{2}$ has variation of the presence percentage at differentiation of the preparation time, as shown in the following (Nabil et al. 2018). So, the physical and chemical properties of each porous $\mathrm{SiO}_{2}$ powder product are varying as a result of changing the material construction (Davraz and Gunduz 2005).

At 6 , and 3 wt $\% \mathrm{KOH}$, as shown in Figure 3, the FTIR spectra listed the broad transmittance band centered at $3443 \mathrm{~cm}^{-1}$ that correspond to the $\mathrm{O}-\mathrm{H}$ stretching vibrational band (Smit et al. 2017) of hydrogen-bonded water molecules (H-O-H) (Nabil and Motaweh 2015). The band at $1633 \mathrm{~cm}^{-1}$ is due to the bending vibration of water molecules (Nabil et al. 2018). The shoulder at $2338 \mathrm{~cm}^{-1}$ was assigned to the stretching vibrations of $\mathrm{Si}-\mathrm{OH}$ groups in the structure of amorphous $\mathrm{SiO}_{2}$ (Musić et al. 2011), which also confirm the XRD data as shown in Figure 1e. The presence of the $\mathrm{Si}-\mathrm{OH}$ group is proof of bonded water. The very strong and broad FTIR band at $1082 \mathrm{~cm}^{-1}$ is usually assigned to $\mathrm{Si}-\mathrm{O}-\mathrm{Si}$ asymmetric stretching vibrations (Kashyout et al. 2013), and (Kashyout et al. 2018). The band at $789 \mathrm{~cm}^{-1}$ can be assigned to $\mathrm{Si}-\mathrm{O}-\mathrm{Si}$ symmetric stretching vibrations (Trivedi et al. 2015), whereas the FTIR band at $470 \mathrm{~cm}^{-1}$ is due to $\mathrm{O}$ $\mathrm{Si}-\mathrm{O}$ bending vibrations (Hernández-Ortiz et al. 2015). Of course, the crystalline porous $\mathrm{SiO}_{2}$ has more pronounced FTIR bands with narrower line widths (Nabil et al. 2018), which confirm the XRD data as shown in Figure 2g. The strong transmittance bands at 3441 and $1089 \mathrm{~cm}^{-1}$ correspond to the terminal $-\mathrm{OH}$ groups (Nabil et al. 2017).

Figure 3. Fourier Transform Infrared Spectra of the Precipitated Porous $\mathrm{SiO}_{2}$ Powders obtained with Different KOH Concentrations prepared by Wet Chemical Etching and Slow Drying at Room Temperature; a)Amorphous Silica - b) Crystalline Silica

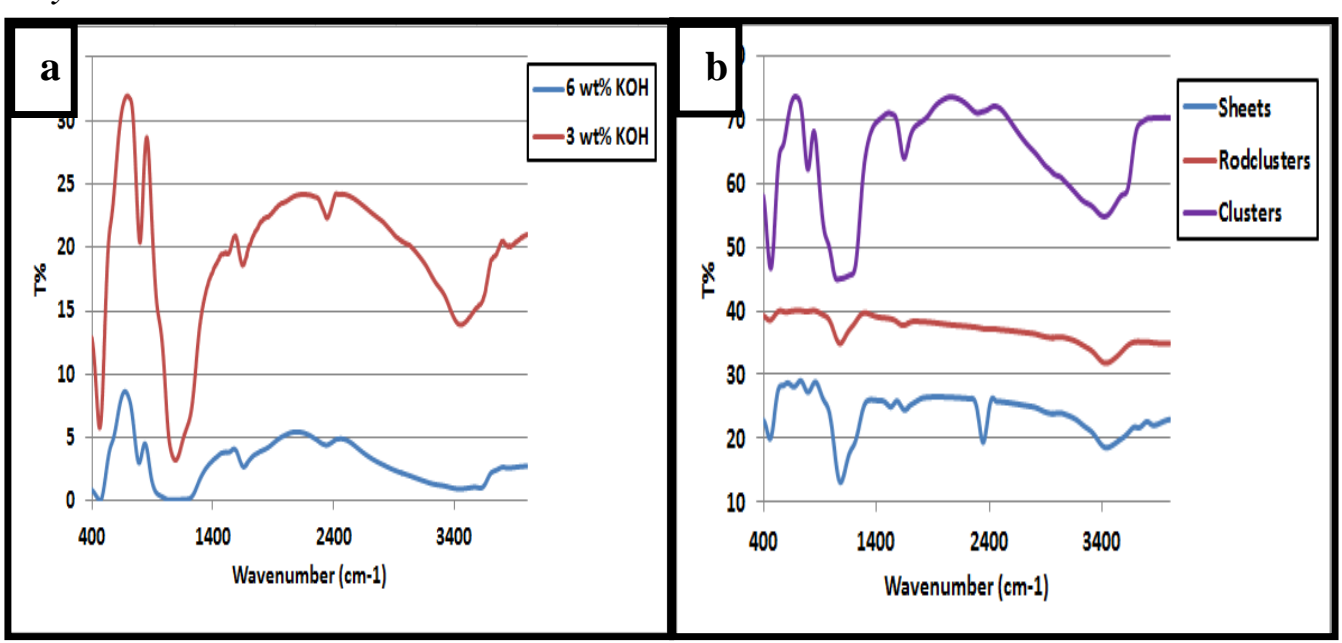

Porous $\mathrm{SiO}_{2}$ powder is one of the best materials used to remove organic compounds from wastewater (Jiang et al. 2018), as shown in Figure 4. For removing the excess oils or dyes from the industrial wastewater (Ahmad et al. 2002), the porous $\mathrm{SiO}_{2}$ is suitable for that. Figure 4 a shows the removing process 
of the soybean oil using amorphous porous $\mathrm{SiO}_{2}$ powder (Cho and Moon 2017). The removal percent is $100 \%$ at using $0.7 \mathrm{gm} / \mathrm{L}$ (at $5 \mathrm{vol} \%$ soybean oil), which is a promising result. On the other hand, using the crystalline porous $\mathrm{SiO}_{2}$ is useless, as shown in Figure $4 \mathrm{~b}$. That as a result of the exposed surface area value of the porous $\mathrm{SiO}_{2}$ as an adsorbed material, which is previously described in Figure 1 and Figure 2. Noticeable, the size of the soybean oil molecule is large with respect to the molecule size of congo red dye (Kashyout et al. 2015). But the suitable value used is the $33.3 \mathrm{gm}$ of crystalline porous $\mathrm{SiO}_{2} / 1$ (at congo red concentration $50 \mathrm{ppm}$ ). The removal percent of dye is $99.8 \%$, as shown in Figure $4 \mathrm{c}$.

So, the synthesis amorphous porous $\mathrm{SiO}_{2}$ is most suitable for removing the high viscosity organic liquids as soybean oil. On the other hand, the synthesis crystalline porous $\mathrm{SiO}_{2}$ is most suitable for removing the low viscosity organic liquids as Congo Red dye solution. The adsorption process depends on the particle size value of each liquid.

Figure 4. FTIR Spectra of the Soybean Oil Removal Using; a) Amorphous Porous $\mathrm{SiO}_{2}$, b) Crystalline Porous $\mathrm{SiO}_{2}$, and c) UV Spectra of the Congo Red Removal Use Crystalline Porous $\mathrm{SiO}_{2}$

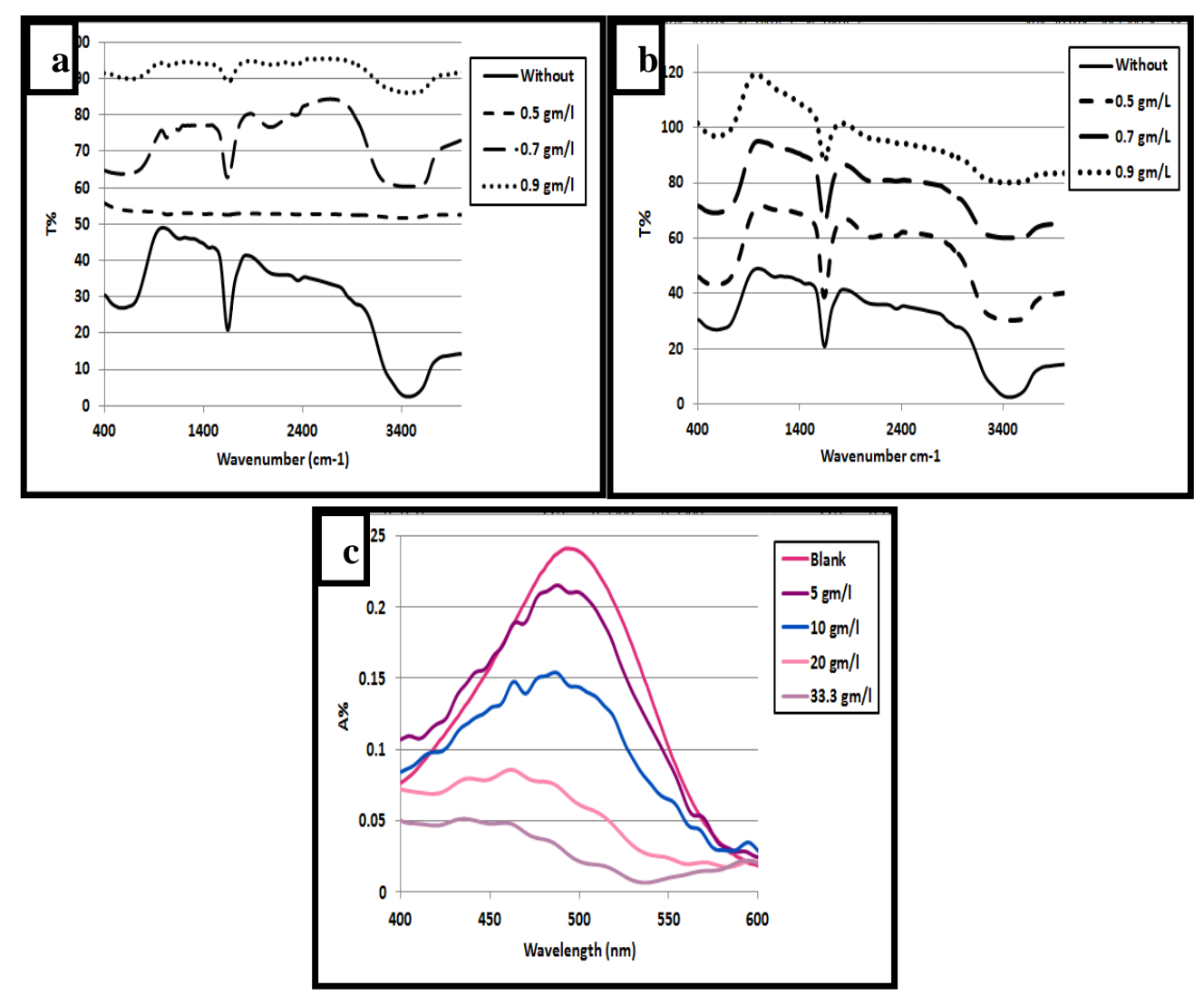




\section{Conclusions}

Porous $\mathrm{SiO}_{2}$ powder is prepared by dual technique (alkali chemical etching process and the ultra-sonication technique). The results of this study are presenting the importance of the porous $\mathrm{SiO}_{2}$ morphology and crystanillity. So, the ability of the adsorption process for different organic compounds (as soybean oil and Congo red dye) is depending on the active surface area of the porous $\mathrm{SiO}_{2}$ powder with different architectures. The amorphous type of porous $\mathrm{SiO}_{2}$ is the most suitable one for all organic impurities removal from industrial wastewater that as a result of its large pore sizes (micrometer range). So, it's easy to adsorb micro and nanometer molecule's sizes. On the other hand, the crystalline type of synthesis porous $\mathrm{SiO}_{2}$ powder isn't suitable for adsorption process to soybean oil molecules as a result of its molecules size which is in micrometer range. Then, it's agreed only for Congo red dye molecule removal because of its molecular size (nanometer range).

\section{References}

Abou-Rida M, Harb F (2014) Synthesis and characterization of amorphous silica nanoparitcles from aqueous silicates using cationic surfactants. Journal of Metals, Materials and Minerals 24(1): 37-42. DOI=10.14456/jmmm.2014.7.

Ahmad A-L, Harris WA, Syafiie, Seng, OB (2002) Removal of dye from wastewater of textile industry using membrane technology. Jurnal Teknologi 36: 31-44. DOI=10.11113/jt.v36.581.

Ahmad A, Clowes R, Willneff E, Myers P, Zhang H (2010) Porous silica spheres in macroporous structures and on nanofibres. Philosophical Transactions of the Royal Society A 368(1927): 4351-4370. DOI=10.1098/rsta.2010.0136.

Aminu AS, Gimba CE, Kagbu J, Turoti M, Itodo AU, Sariyya AI (2010) Sorption efficiency study of Pesticide adsorption on Granulated activated carbon from Groundnutshell using GC/MS. Electronic Journal of Environmental, Agricultural and Food Chemistry 9(7): 1222-1231.

Bernardos A, Kouřimská L (2013) Applications of mesoporous silica materials in food. Journal of Food Science 31(2): 99-107. DOI= 10.17221/240/2012-CJFS.

Castillo SIR, Ouhajji S, Fokker S, Erné BH, Schneijdenberg CTWM, Thies-Weesie DME, Philipse AP (2014) Silica cubes with tunable coating thickness and porosity: From hematite filled silica boxes to hollow silica bubbles. Microporous and Mesoporous Materials 195: 75-86.

Chaemiso TD, Nefo T (2019) Removal methods of heavy metals from laboratory wastewater. Journal of Natural Sciences Research 9(2): 36-42. DOI=10.7176/JNSR.

Cho Y-S, Moon J-W (2017) Collection of industrial oil using nanoparticles and porous powders of silica. Arch. Metall. Mater. 62: 1371-1375. DOI=10.1515/amm-20170211.

Davraz M, Gunduz L (2005) Engineering properties of amorphous silica as a new natural pozzolan for use in concrete. Cement and Concrete Research 35(7): 1251-1261. DOI=10.1016/j.cemconres.2004.11.016.

Feng X, Fryxell GE, Wang LQ, Kim AY, Liu J, Kemner KM (1997) Functionalized monolayers on ordered meso porous supports. Science 276(5314): 923-926. DOI= 10.1126/science.276.5314.923. 
Hernández-Ortiz M, Hernández-Padrón G, Bernal R, Cruz-Vázquez C, Castaño VM (2015) Nanocrystalline mimetic opals: synthesis and comparative characterization vs. natural stones. International Journal of Basic and Applied Sciences 4(2): 238-243. DOI=10.14419/ijbas.v4i2.4174.

Jiang N, Shang R, Heijman SGJ, Rietveld LC (2018) High-silica zeolites for adsorption of organic micro-pollutants in water treatment: A review. Water Research 144: 145161. DOI=https://doi.org/10.1016/j.watres.2018.07.017.

Jokić S, Sudar R, Svilović S, Vidović S, Bilić M, Velić D, Jurković V (2013) Fatty acid composition of oil obtained from soybeans by extraction with supercritical carbon dioxide. Czech Journal of Food Sciences 31(2): 116-125. DOI=10.17221/8/2012CJFS.

Joni IM, Nulhakim L, Vanitha M, Panatarani C (2018) Characteristics of crystalline silica $\left(\mathrm{SiO}_{2}\right)$ particles prepared by simple solution method using sodium silicate $\left(\mathrm{Na}_{2} \mathrm{SiO}_{3}\right)$ precursor. Journal of Physics: Conference Series 1080, (2018): 012006-012012. DOI=10.1088/1742-6596/1080/1/012006.

Juárez GS, Barojas EG, González EQ, Mora ES, López JAL (2016) Oxidized porous silicon as a non-interfering support for luminescent dyes. Mesoporous Biomaterials 3(1): 61-66. DOI=https://doi.org/10.1515/mesbi-2016-0008.

Kashyout A-HB, Soliman HMA, Nabil M, Bishara AA (2013) Fabrication of nano-porous silicon using alkali etching process. Materials Letters 100: 184-187. DOI=http://dx.doi.org/10.1016/j.matlet.2012.12.107.

Kashyout A-HB, Soliman HMA, Nabil M, Bishara AA (2015) Impact of Congo red dye in nano-porous silicon as $\mathrm{pH}$-sensor. Sensors and Actuators $B$ 216: 279-285. DOI=http://dx.doi.org/10.1016/j.snb.2015.03.099.

Kashyout A-HB, Nabil M (2018) Production of high throughput nano-porous silicon (NPS) powder with different architectures. Materials Chemistry and Physics 216: 454-459. DOI=https://doi.org/10.1016/j.matchemphys.2018.05.048.

Kaykhaii M, Sasani M, Marghzari S (2018) Removal of dyes from the environment by adsorption process. Chemical and Materials Engineering 6(2): 31-35. DOI=10.13189/cme.2018.060201.

Lee J-Y, Chen C-H, Cheng S, Li H-Y (2016) Adsorption of $\mathrm{Pb}$ (II) and Cu(II) metal ions on functionalized large-pore mesoporous silica. International Journal of Environmental Science and Technology 13(1): 65-76. DOI=10.1007/s13762-0150841-y.

Lisowska-Oleksiak A, Nowak AP, Wicikowsk B (2014) Aquatic biomass containing porous silica as an anode for lithium ion batteries. RSC Advances 4(76): 4043940443. DOI=10.1039/C4RA06420H.

Mahmoodi NM, Maghsoudi A, Najafi F, Jalili M, Kharrati H (2014) Primary-secondary amino silica nanoparticle: synthesis and dye removal from binary system. Desalination and Water Treatment 52: 7784-7796. DOI=10.1080/19443994. 2013.833872.

Morsi RE, Mohamed RS (2018) Nanostructured mesoporous silica: influence of the preparation conditions on the physical-surface properties for efficient organic dye uptake. Royal Society Open Science 5(3): 172021-172036. DOI=0000-0002-36952738.

Musić S, Vinceković NF, Sekovanić L (2011) Precipitation of amorphous $\mathrm{SiO}_{2}$ particles and their properties. Brazilian Journal of Chemical Engineering 28(1): 89-94. DOI=10.1590/S0104-66322011000100011.

Nabil M, Motaweh HA (2015) Silica nanoparticles preparation using alkali etching process. Applied Mechanics and Materials 749: 155-158. DOI=10.4028/www.scien tific.net/AMM.749.155. 
Nabil M, Elnouby M, Gayeh N, Sakr AH, Motaweh HA (2017) Enhancement of porous silicon photoluminescence using (Ni) Treatment. IOP Conference Series: Materials Science and Engineering 248: 012001-012008. DOI=10.1088/1757-899X/248/ $1 / 012001$.

Nabil M, Motaweh HA (2018) Porous silicon powder as an adsorbent of heavy metal (Nickel). AIP Conference Proceedings 1957: 020005-020010. DOI=10.1063/1. 5034324.

Nabil M, Mahmoud KR, El-Shaer A, Nayber HA (2018) Preparation of crystalline silica (quartz, cristobalite, and tridymite) and amorphous silica powder (one step). Journal of Physics and Chemistry of Solids 121: 22-26. DOI=https://doi.org/10.1016/j.jpcs. 2018.05.001.

Nabil M, Motaweh HA (2019) Shape control of silica powder formation. Journal of Materials Science and Chemical Engineering 7(3): 49-55. DOI=https://doi.org/10.42 36/msce.2019.73004.

Narayan R, Nayak UY, Raichur AM, Garg S (2018) Mesoporous silica nanoparticles: a comprehensive review on synthesis and recent advances. Pharmaceutics 10(3): 2-49. DOI=10.3390/pharmaceutics10030118.

Nikolić MP, Ribić-Zelenović L, Trišović T, Stanojević-Nikolić S (2016) Synthesis and characterization of porous silica particles for bioseparation application. Acta. Agriculturae Serbica XXI(41): 47-55. DOI=10.5937/AASer1641047N.

Nwabueze TU, Okocha KS (2008) Extraction performances of polar and non-polar solvents on the physical and chemical indices of African breadfruit (Treculia africana) seed oil. African Journal of Food Science 2: 119-125. DOI=e http://www. academicjournals.org/ajfs.

Rovani S, Santos JJ, Corio P, Fungaro DA (2018) Highly pure silica nanoparticles with high adsorption capacity obtained from sugarcane waste ash. ACS Omega 3(3): 26182627. DOI=10.1021/acsomega.8b00092.

Russo L, Colangelo F, Cioffi R, Rea I, Stefano LD (2011) A mechanochemical approach to porous silicon nanoparticles fabrication. Materials 4(6): 1023-1033. DOI=10.3390 /ma4061023.

Santos RG, Loh W, Bannwart AC, Trevisan OV (2014) An overview of heavy oil properties and its recovery and transportation methods. Brazilian Journal of Chemical Engineering 31(3): 571-590. DOI=10.1590/0104-6632.20140313s0000 1853.

Sharma YC, Upadhyay USN, Gode F (2009) Adsorptive removal of a basic dye from water and wastewater by activated carbon. Journal of Applied Sciences in Environmental Sanitation 4(1): 21-28. DOI=10.1016/j.desal.2007.05.018.

Singh LP, Agarwal SK, Bhattacharyya SK, Sharma U, Ahalawat S (2011) Preparation of silica nanoparticles and its beneficial role in cementitious materials. Nanomaterials and Nanotechnology 1(1): 44-51. DOI=10.5772/50950.

Smit WJ, Tang F, Nagata Y, Sanchez MA, Hasegawa T, Backus EHG, Bonn M, Bakker HJ (2017) Observation and identification of a new $\mathrm{OH}$ stretch vibrational band at the surface of ice. Journal of Physical Chemistry Letters 8(15): 3656-3660. DOI=10.10 21/acs.jpclett.7b01295.

Trivedi MK, Branton A, Trivedi D, Shettigar H, Bairwa K, Snehasis Jana S (2015) Fourier transform infrared and ultraviolet-visible spectroscopic characterization of biofield treated salicylic acid and sparfloxacin. Natural Products Chemistry \& Research 3(186): 5 - 11. DOI=http://dx.doi.org/10.4172/2329-6836.1000186.

Vuong DH, Zhang HQ, Sarica C, Li M (2009) Experimental study on high viscosity oil/water flow in horizontal and vertical pipes. Society of Petroleum Engineers 124542. DOI=10.2118/124542-MS. 
Xiong Q, Baychev TG, Jivkov AP (2016) Review of pore network modelling of porous media: Experimental characterisations, network constructions and applications to reactive transport. Journal of Contaminant Hydrology 192: 101-117. DOI=https:// doi.org/10.1016/j.jconhyd.2016.07.002.

Yan D, Cheng S, Zhuo RF, Chen JT, Feng JJ, Feng HT, Li HJ, Wu ZG, Wang J, Yan PX (2009) Nanoparticles and 3D sponge-like porous networks of manganese oxides and their microwave absorption properties. Nanotechnology 20(10): 105706-105715. DOI=10.1088/0957-4484/20/10/105706.

Zakarya A, Matos BR, De-Florio DZ, Licoccia S, Traversa E, Esposito V, Santiago EI, Fonseca FC (2009) Nafion-mesoporous silica as electrolyte for ethanol fuel cells. ECS Transactions 25(1): 853-860. DOI=10.1149/1.3210639. 
